\title{
Integrated SASSCAL research to assess and secure current and future water resources in Southern Africa
}

\author{
JÖRG HELMSCHROT \& NORBERT JÜRGENS
}

Biodiversity, Evolution and Ecology of Plants (BEE), University of Hamburg, Ohnhorststr. 18, D-22609 Hamburg, Germany

joerg.helmschrot@sasscal.org

\section{INTRODUCTION}

Climate change will affect current water resources and food security in sub-Saharan Africa. Considering ongoing changes in land management and population growth as well as projected climate scenarios, the overall challenge in the southern African region is to secure water at sufficient quality and quantity for both the stability of ecosystems, with their functions, and services and for human well-being (potable water, irrigation water, and water for industrial use). Thus, improved understanding of the linkages between hydrological (including hydrogeological) components of ecosystems and society is needed as a precondition to develop sustainable management strategies for integrated water resources management in this data scarce region. With initial funding through the Federal Ministry of Education and Research (BMBF) of Germany, 88 research projects of the SASSCAL Initiative (Southern African Science Service Centre for Climate Change and Adaptive Land Management; www.sasscal.org) focus on providing information and services allowing for a better understanding and assessment of the impact of climate and land management changes in five thematic areas: climate, water, agriculture, forestry and biodiversity.

\section{SASSCAL WATER RESEARCH ACIVITIES}

Water-related research activities in SASSCAL aim at improving our knowledge of the complex interactions and feedbacks between surface and groundwater dynamics and resources as well as land surface processes in selected regions of the participating countries (Angola, Botswana, Namibia, South Africa and Zambia). The main objective of this joint and integrated research effort of 17 water tasks is to develop reliable hydrological and hydrogeological baseline data along with a set of analytical methods to strengthen the research capacity of the water sector of the Southern African region. Thereby, SASSCAL contributes to the implemention of integrated water resources management strategies for improved transboundary river management and resources usage in the perspective of global climate and land management changes.

The research activities within the water theme can be summarized in three key research areas:

- base data observation/monitoring in experimental catchments in Angola (new monitoring infrastructure establishments in Rio Giraul basin), Botswana (expansion of existing monitoring infrastructure in the Notwane basin) and South Africa (continuing and extension of long-term observations in four experimental basins);

- basic research in the fields of erosion and sedimentation assessments and land-use/climate change impacts at watershed level in selected regions;

- integrated and interdisciplinary high level research in the fields of groundwater (mapping, quality and quantity, use), flood (mapping, monitoring, projection and risk assessments) as well as water demand analysis.

In agreement with tasks from the other thematic areas, five regional hotspots have been identified for water research in the SASSCAL research portfolio. The focal areas in the water theme include: (i) Northern Namibia/South Angola; (ii) Central Angola; (iii) the broader KAZA transboundary region including the upper Zambezi River basin, upper Congo River basin, Okavango River basin and Chobe River basin; (iv) Southern Botswana and Limpopo River basin; and (v) Western Cape, South Africa (see Fig. 1). 
Figure 1 illustrates the regional focus and topics of the ongoing studies conducted by various SASSCAL research teams. The case studies on flood monitoring using remote sensing products, hydrological risks assessments and early warning systems for floods, integrated hydrological modelling efforts, groundwater-surface water interactions and various hydrological process studies in different ecosystems, all at various (local, regional, national and international) and temporal (short-term, long-term, climate projection) scales were successfully started in 2013 . With this variety of partially-linked research efforts we demonstrate our interdisciplinary research approach as the prerequisite to addressing the complexity of interacting drivers and processes affecting land and water resources in Southern Africa. The integration of these joint research efforts with findings from other thematic areas, e.g. in the field of optimized land management, deforestation and restoration, ecosystem stability and resilience, climate projections, food production and security, will allow for a better understanding and assessment of global change related environmental threats and resulting societal challenges in the southern African region. More information can be found on www.sasscal.org.

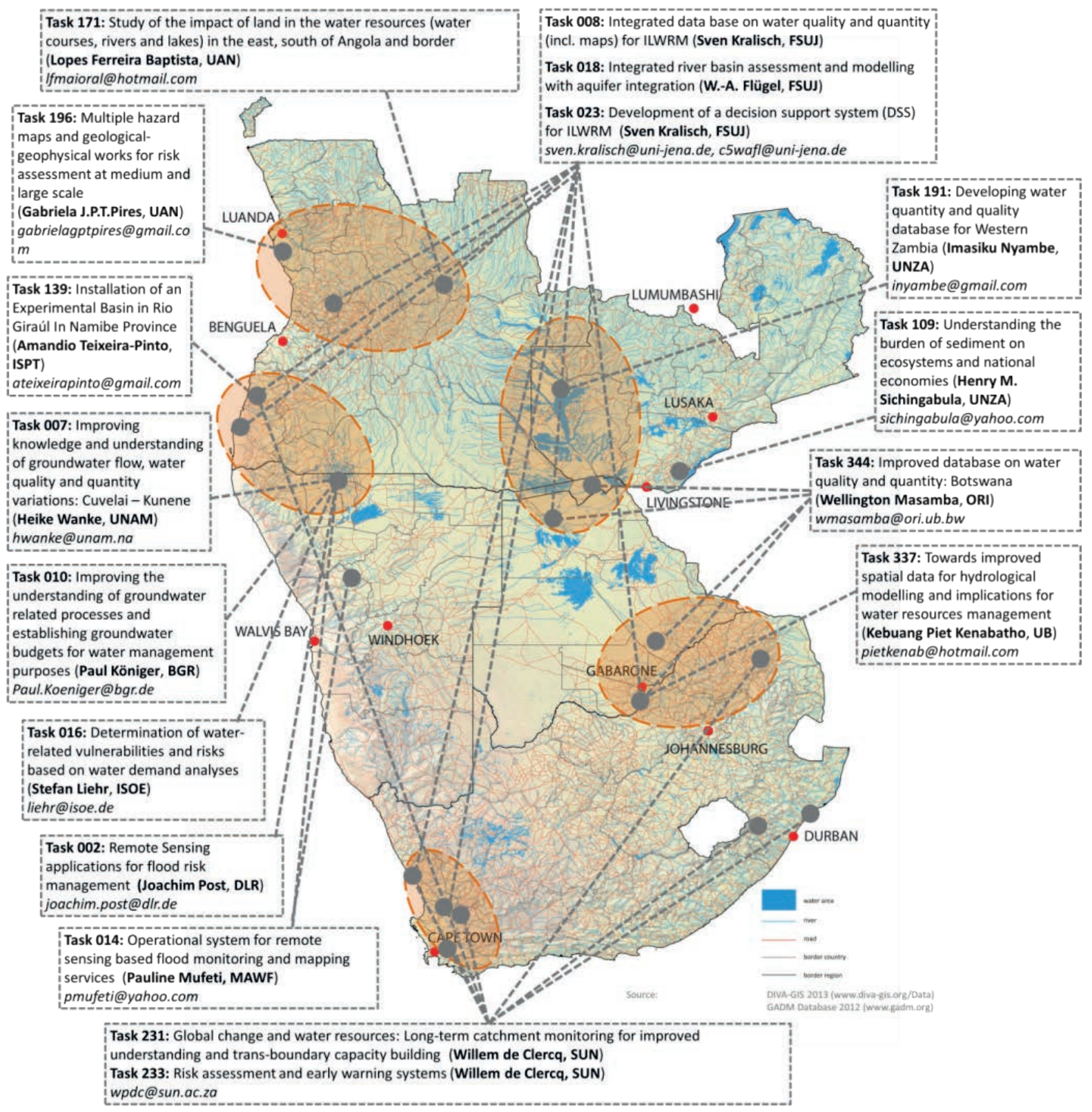

Fig. 1 SASSCAL regional hotspots and the topics of 17 water-related subprojects in SASSCAL. 